F O R E W O R D

\title{
To Inhabit a World
}

\author{
David Pettigrew
}

One is able to discern a certain trajectory in the work of Jean-Luc Nancy, from a thinking of community to a thinking of world, a trajectory that can be said to begin with his text The Inoperative Community, ${ }^{1}$ which first appeared in French in 1986, and which culminates in this new book, What's These Worlds Coming To? [Dans quels mondes vivons-nous?]. ${ }^{2}$ Significantly, in the movement of his thought from community to world, Nancy has nonetheless remained concerned with the theme of being-with, which he has drawn from Heidegger's existential analysis of Mitsein. ${ }^{3}$ In The Inoperative Community, Nancy cautions that our being-with others "is not a communion ... nor even a communication as this is understood to exist between subjects. But these singular beings are themselves constituted by sharing, they are distributed and placed, or rather spaced, by the sharing that makes them others" (IC 25). These singular others, he writes, communicate by "not 'communing" (ibid., my emphasis). The communication of "sharing" takes place in this "very dis-location" (ibid.). Any community in this sense would be composed of singular existences that "share" the exposure of their singularity in their being-toward-death, or finitude. What is "communicated" is nothing other than the exposition of singularity. For Nancy, "community" means that there is "no singular being without another singular being" (IC 28). Nancy writes, "This exposure, or this exposing-sharing, gives rise, from the outset, to a mutual interpellation of singularities prior to any address in language (though it gives this latter its first condition of possibility). Finitude compears, that is to say it is exposed: such is the essence of community" (IC 29). 
What is shared, however, in this paradoxical sense, is the impossibility of sharing. Singular beings are given, he writes, "without a bond and without a communion" (IC 29). For Nancy, the being-with or "being-incommon" of an inoperative community is a community that, as such, can never cohere. What we might refer to as the in-coberence of community is crucial for Nancy's thinking. "At every instance," Nancy writes, "singular beings share their limits, share each other on their limits" (IC $4 \mathrm{I})$. Nancy opposes, then, the thinking of the limit of community, or the in-coherence of community, to an "absolute immanence" of community. For Nancy, it is just such an immanence that is "the stumbling block to a thinking of community," since it coheres in its immanence as a "totalitarianism," a totalitarianism that Nancy's thinking of an inoperative community seeks to avoid ( $\left.\mathrm{IC}_{3}\right)$.

In his text Being Singular Plural (2000), which originally appeared in French in 1996, Nancy advances a thought of a world that springs forth from a plurality of singular origins "everywhere and in each instant." 4 "The origin of the world," he asserts, "occurs at each moment of the world. It is the each time of Being, and its realm is the being-with of each time with every [other] time. The origin is for and by way of the singular plural of every possible origin" (BSP 83). For Nancy, the world is composed of the singularity of the plurality of primordial beginnings: "Each being belongs to the (authentic) origin, each is originary (the springing forth of the springing forth itself) ..." (ibid.). The springing forth of the singularities that is at the origin of the world involves, as in the case of The Inoperative Community, a sharing. There is a sharing of origins that, for Nancy, is a thinking of being-with, a sharing that is intercorporeal. The "intercorporeal," Nancy writes, "exposes bodies according to their being-with-one another . . . amongst themselves [entre eux] as origins" (BSP 84). One mode of this exposition is language. Yet such an exposition does not entail a prosaic mode of communication. What language expresses "is the exposing of plural singularity" (ibid.). In language, "all of being is exposed as its meaning $[$ sens $]$... as the originary sharing according to which a being relates to a being, the circulation of a meaning of the world [sens du monde] that has no beginning or end" (BSP 84). The relation of singular beings is, "each time, the punctuality of a 'with' that establishes a certain origin of meaning [sens]" (BSP 85). 
This coexposition of the body and language is further articulated in Nancy's treatment of the body and writing in Corpus. ${ }^{5}$ For Nancy the "exscription [excription]" of the body entails a "being placed outside the text as the most proper movement of its text ( $C_{\text {I I }}$ ). He writes, "we have to write from a body that we neither have nor are, but where being is exscribed" ( $C$ I 9$)$. In the process of writing we are undone and we "lose of our footing," since, in the exscription

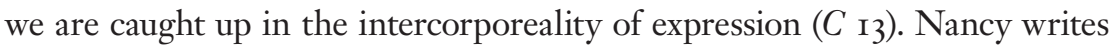
that there is "no writing that doesn't touch" ( $C$ II $)$, and in this touching there is a "breakthrough [effraction]" as the body "exposes a breakthrough of sense" ( $C 25)$. Nancy addresses this conceptual breakthrough proper to the body with the neologism "expeausition," a term that replaces the phoneme "po" (in exposition) with the homonymically equivalent French word for skin, "peau” (expeausition) $\left(C_{33}\right)$.

For Nancy, then, the thinking of the origin and sense of the world, in Being Singular Plural, entails a thinking of being-with. Indeed, the intercorporeal exposition of language "exposes the world and its proper being-withall-beings in the world" (BSP 85). It is nothing less than this intercorporeal ex-position that makes "the world 'hold' or 'consist' in its proper singular plurality" (ibid.). ${ }^{6}$ Thus, Nancy's thinking of community in The Inoperative Community, in the sense that it involves the sharing-out of singular beings in their limits or finitude, is intertwined with his thinking of world in Being Singular Plural. Moreover, Being Singular Plural, with its thinking of the exposition of world on the basis of a being-with, can be said to serve as a bingework between Nancy's thinking of community and his thinking of world.

With his text The Sense of the World (1997), which originally appeared in French in 1993, Nancy identifies a "becoming worldwide [mondialisation] of the world," a "cosmopolitanism" and "teletechnism" that is tearing the sense of the world "to shreds." Nancy seeks to salvage the sense of the world, grasping at the "only chance for sense and its only possible sense" beyond the structures and restrictions of grammar in the "abandonment of sense, as the opening of the world" ( $\left.S W_{3}\right)$. Nancy is engaged with this loss of the sense of the world as he writes: "[T]he world of sense is culminating today in the unclean ['immonde $]^{8}$ and in nonsense. It is heavy with suffering, disarray, and revolt" ( $S W$ 9). For Nancy, to make sense of the sense of the world, to "sense oneself making sense [se sentir faire sens], and even more, to sense 
oneself as the engenderment of sense [se sentir comme l'engendrement du sens] . . . is without a doubt the ultimate stake of philosophy" ( $S W$ I62). To make sense of the world means to encounter the origin "where it $[c a]$ opens itself" ( $S W$ I60). In other words, Nancy insists on the singularity of the opening or origin of the world that is always already in excess of any other or any previous meaning. This excess is expressed in "the exscription of all words: the takingplace-there of their sense, of all their senses, 'outside,' here” (ibid.). Making sense would realize this intercorporeal dehiscence of sense "through the common being-as-act of sensing and sensed" $\left(S W{ }_{7} 8\right)$. The sense of the world would emerge as "a differentiated articulation of singularities that make sense in articulating themselves along the edges of their articulation" $\left(S W{ }_{7} 8\right)$. Nancy points, indeed, to an "active dehiscence of the act of sensing: that is to say, to ek-sisting in general" ( $S W 79)$.

In his text, The Creation of the World or Globalization (2007), which first appeared in French in 2002, Nancy addresses the sense of the world in terms of the crisis of globalization. He provides a sharp distinction between "globalization," on the one hand, and an authentic "world-forming," on the other hand. Rejecting the un-world [l'immonde], Nancy emphasizes the freedom of singular plural beginnings when he writes, "To create the world means: immediately, without delay, reopening each possible struggle for a world, that is, for what must form the contrary of a global injustice against the background of general equivalence" $(C W 54)$. The suppression of the creation of meaning, of "each possible struggle for a world," would, for Nancy, constitute injustice. To the "un-world" of technology wielded by metaphysics, Nancy opposes a world that is always under formation. For Nancy, "What forms a world today is exactly the conjunction of an unlimited process of an eco-technological enframing and of a vanishing of the possibilities of forms of life and of common ground" ( $C W$ 95). Justice, for Nancy, would be engendered by the inexhaustible creation of meaning.

In our present text, What's These Worlds Coming To? Nancy addresses, among other things, the sense of the world in terms of the crisis of its technological enframing. His reflections may be read as a reference to what Heidegger named das Ge-Stell in the Bremen lectures. ${ }^{9}$ For Heidegger, das Ge-Stell "essences as the plundering drive that orders the constant orderability of the complete standing reserve" ( $\left.B L_{3} \mathrm{I}\right)$. Heidegger asserts that the 
standing reserve "persists in requisitioning [Bestellen]," as a "machination of the human, executed in the manner of an exploitation" ( $B L$ 28). Yet this machination is not a strategy carried out by humans but is rather one that envelops humans. Through the requisitioning of das Ge-Stell, humans and nature are "machined," in a sense, into pieces of the standing reserve, and rendered equivalent, interchangeable, and replaceable: "one piece can be exchanged for the other" ( $B L$ 35). In the ordered equivalence of the standing reserve, "everything stands in equal value" $(B L 42)$. This interchangeability and replaceability of the standing reserve [Bestand] could be referred to, for example, as an alienation of Dasein, in this context, from its proper sense making.

For Nancy as well, the technological frames the world as in a machine. Moreover, the machine is not separate from the world but the world itself becomes a technologized machine. "Technology," he writes, "is a structuration of ends-it is a thought, a culture, or a civilization, however one wants to word it - of the indefinite construction of complexes of ends that are always more ramified, intertwined, and combined, but, above all, of ends that are characterized by the constant redevelopment of their own constructions" $\left(W T W_{44}\right)$. In other words, the technologized machine, or apparatus, has no end but its own end, an end without sense and without social value, an end that leads to market volatility or to the destruction of worlds as in the case of genocide. ${ }^{10}$ Within the machine is a hypertrophic construction that makes it less and less possible to distinguish between subject and object, human, nature and world, entailing moreover a loss of agency, responsibility, and sense. All these elements are dispersed out into the machine, into what Nancy identifies as an "ecotechnology that our ecologies and economies have already become" (WTW 54). What is at stake in this ecotechnology, for Nancy, is nothing less than the sense of the world. The questioning of the sense of the world offered in this new book, then, takes its place in Nancy's ongoing inquiry, as he writes, "The sense of 'world' is not only undecided and multiple-it has become the crucial point where all of the aspects and stakes of 'sense' in general become tied together" $(W T W \mathrm{I})$.

Perhaps in the context of What's These Worlds Coming To? the "beingwith" is enacted in the co-authorship of the text with Aurélien Barrau, who 
writes alternating chapters. Further, the with of a being-with, or a livingwith, appears in a recent interview with Pierre Philippe Jandin, titled $L a$ possibilité d'un monde: dialogue avec Pierre-Philippe Fandin..$^{11}$ In the interview, Jandin asks Nancy about his collaboration with Barrau. Nancy replies that while Barrau is an astrophysicist, he is "also a philosopher" ( $\left.P M_{34}\right)$. Nancy states, moreover, that he has learned from Barrau that astrophysics is "obliged to give thought to a plurality of worlds," that is, to a "plurivers" or a "multivers" as opposed to a "univers" (ibid.). This reference to a plurality of worlds offers some perspective on the meaning of the new book's enigmatic title (Dans quels mondes vivons-nous?). Perhaps being-with can still be heard in the French title of the text, that is, through the "we" [nous], if the title is translated literally as "What worlds do we live in?" Nancy suggests in La possibilité d'un monde ... that we need to learn to inhabit the world anew, "to be in the world" [in-der-Welt-sein] necessarily engaged in the circulation of sense that makes a world ( $P M_{3}$ I $)$. Such a "babitus," he states, "is not far from an ethos," and he insists, moreover, that "what we need is an ethics of the world" (ibid.). Nancy asserts that "The world is the possibility of circulation of sense and we have to make a world, and remake a world" (ibid., my emphasis).

Nancy's gesturing toward an "ethics of the world" is evocative of his essay titled "Heidegger's 'Originary Ethics." "12 In that context, Nancy referred to a "thinking" that is the "experience of this absolute responsibility for sense" (HPP 80, my emphasis). For example, absolute responsibility would entail "opening oneself to making sense as such" (HPP 8I). For Nancy, an originary ethos would entail a dwelling with a responsibility for making sense and for a possibility for making sense (cf. HPP 82). This responsibility for sense making would be an origin of a world to be, as Nancy suggested, made and remade. In the context of an originary ethics, Nancy refers to a "making sense in common," which is nothing less than "finitude as sharing" (HPP 83). A finitude in sharing is what Nancy has referred to as a being singular plural of a making sense that is at the origin of the world. Indeed, in a 2008 essay titled "The Being-with of the Being-There," Nancy asserts that "Dasein is a singular, unique possibility of forming/letting a proper meaning of the world ... open." 13 Perhaps what Nancy undertakes in that text is not so much a strict interpretation of Heidegger's treatment of Dasein and being-with, as it is a palpation of the possibilities and the stakes of being-with: 
"[I]t is exactly at the site of the with that both the opportunity and risk of existence are manifest" ( $R F$ I26).

In the "Preamble" of this new book, Nancy and Aurélien raise questions with respect to the sense of the world. Specifically, the authors identify a certain threefold crisis. They state, first, that in our time the cosmos can no longer be represented as a coherent whole or unity. Second, they state that the world lacks a definite and manageable order according to which we would address nature or culture. Third, they suggest that the world has become diversified and multiple as never before, affecting the complexity of our interactions (with life, matter, space, and time), and destabilizing all forms of civilization (cf. WTW I). The authors lament that in a so-called globalized world, our world and our modes of life are "more diffracted, scattered, heterogeneous, and even unidentifiable" $\left(W T W_{3}\right)$. It is in this context that Nancy gives thought to the sense of the world in crisis. In Chapter I, his approach to this question is to give thought to the "plus d'un" of the world, an expression borrowed from Derrida that, in this context, means or suggests "more than one." Nancy clarifies that this "more than one" is not "more" in the sense of adding one to another in a countable series. Rather, for Nancy, the "more than one" hearkens to Derrida's thinking of "dissemination" and "différance," in order to encounter the meaning or sense of the world as an "excess of sense" (WTW I2). Nancy speaks of such a différance, or such an excess, as "l'un excédant," or "the exceeding one" (WTW I8). The world, then, “is," for Nancy, an excess of sense. Nancy's thinking of a world as exceeding or preceding itself is an opening of a critique, on the one hand, of the inappropriateness of the scientific view of the world as a unified object in space with measurable dimensions, or as a container that we are "in," and, on the other hand, a critique of the commercial tendency to objectify and render everything as "merchandise" within a globalized world. Nancy's thinking of a world as exceeding itself is an opening to "sense" itself.

Hence, in the course of his work, Jean-Luc Nancy has undertaken an interrogation of the sense of the world that began with a thinking of community and continued with a thinking of the world. In the course of this trajectory, Nancy has developed a thought of being-with and being-incommon. In the current book, one encounters a sense of being-with in 
terms of a living-with in a world. But for those readers who still have "a taste for the secret," "I4 will not say more about the current book, but instead offer the following passage from the text, to give Jean-Luc Nancy and Aurélien Barrau the last word:

We do not conclude: We open up, we attempt. Dans quel(s) monde(s) vivonsnous? - the ambiguity of whether it is a pluralized singular or a singularized plural is admitted — may be heard in the same key as: "Is there something like a world in which we find ourselves?" Or perhaps: "Of all the possible worlds, which one is ours?" Or might we even understand the "world" in the sense of when one cries out: "The whole world is here!" By which crowd, which pack, which fray are we being carried away? Can one even identify, distinguish, and disentangle such a web?

Whatever the case may be, today one must get in the fray. (WTW 7 ) 